\title{
Optimizing Safety Stock Levels in Modular Production Systems Using Component Commonality and Group Technology Philosophy: A Study Based on Simulation
}

\author{
Kenneth Edgar Hernandez-Ruiz, ${ }^{1}$ Elias Olivares-Benitez, ${ }^{2}$ \\ Jose Luis Martinez-Flores, ${ }^{3}$ and Santiago Omar Caballero-Morales ${ }^{3}$ \\ ${ }^{1}$ Tecnologico de Monterrey Campus Puebla, Via Atlixcayotl No. 2301, Reserva Territorial Atlixcayotl, \\ 72453 Puebla, PUE, Mexico \\ ${ }^{2}$ Universidad Panamericana Campus Guadalajara, Calzada Circunvalación Poniente No. 49, Ciudad Granja, \\ 45010 Zapopan, JAL, Mexico \\ ${ }^{3}$ UPAEP University, 21 Sur 1103 Colonia Santiago, 72410 Puebla, PUE, Mexico
}

Correspondence should be addressed to Elias Olivares-Benitez; eliasolivares@hotmail.com

Received 4 May 2016; Revised 15 July 2016; Accepted 19 July 2016

Academic Editor: Mónica A. López-Campos

Copyright (C) 2016 Kenneth Edgar Hernandez-Ruiz et al. This is an open access article distributed under the Creative Commons Attribution License, which permits unrestricted use, distribution, and reproduction in any medium, provided the original work is properly cited.

\begin{abstract}
Modular production and component commonality are two widely used strategies in the manufacturing industry to meet customers growing needs for customized products. Using these strategies, companies can enhance their performance to achieve optimal safety stock levels. Despite the importance of safety stocks in business competition, little attention has been paid to the way to reduce them without affecting the customer service levels. This paper develops a mathematical model to reduce safety stock levels in organizations that employ modular production. To construct the model, we take advantage of the benefits of aggregate inventories, standardization of components, component commonality, and Group Technology philosophy in regard to stock levels. The model is tested through the simulation of three years of operation of two modular product systems. For each system, we calculated and compared the safety stock levels for two cases: (1) under the only presence of component commonality and (2) under the presence of both component commonality and Group Technology philosophy. The results show a reduction in safety stock levels when we linked the component commonality with the Group Technology philosophy. The paper presents a discussion of the implications of each case, features of the model, and suggestions for future research.
\end{abstract}

\section{Introduction}

Over the past few decades, manufacturing has faced a steady growth in market competition caused mainly by three factors: (1) globalization [1], (2) technological advances, and (3) high demand for customized products [2-4]. To meet this demand and being competitive, the companies have applied as main strategy the offering of a wider variety of products $[1,2,5-$ 9]. However, having a wider variety of products increases the complexity of the organization because it increases the quantity of parts or components that the company must make or buy.
To meet efficiently the high demand of customized products, some researchers $[1,9,10]$ suggest two methods: (1) increasing production capacity and (2) applying modular production systems. Of these strategies, the modular production or modularity is the most popular $[11,12]$. The basic idea of the modularity is to design modules or components standardized with standard interfaces in such a way that they can be combined in a high number of end products to meet customer requirements $[5,13,14]$. A truly modular production system makes it possible to manufacture custom products and to react quickly to customer requirements with 
virtually the same features found in the mass production [1518 ]. One of the main benefits of modularity is that it leads to a reduction of the stock levels.

By using Make to Stock (MTS) and Assemble to Stock (ATS) production approaches, a manufacturer can maintain cycle stock levels according to a forecast demand. However, in an environment with uncertainly, forecasts are not reliable. For this reason, the manufacturers use an investment in safety stocks, which allow them to respond effectively to forecast errors and to overcome or mitigate the risk of stock-outs. The strategy most widely used to minimize the safety stock levels in modular production systems is component commonality, which replaces two or more parts of an end product by a common part [14, 19-23].

The studies for minimizing the safety stock levels in modular production systems began with Collier [24], who argued that, by increasing the degree of component commonality in a modular production system, the costs of operation and the stocks levels can be reduced because larger production batches are created and standardization improved. Thus, Baker [19] proved that the safety stock levels decrease as much as the degree of commonality increases. Baker et al. [25] examined the effect of component commonality on optimal safety stock levels in two products with a two-level inventory model, showing that replacing two unique parts with a common part results in a smaller requirements for the common part. Gerchak and Henig [20] replicated Baker et al. [25] and showed that in Assemble to Order (ATO) systems the stocks of product-specific components always increase when other components are combined with common parts. Gerchak et al. [21] extended the results of Baker et al. [25] in understanding the impact of component commonality on safety stock levels under service level constraints. Hillier [26] analyzed the effects of component commonality in the total cost of a modular production system using a multiperiod model when a common component is significantly more expensive than the unique parts. Chew et al. [27] quantified the impact of component commonality in a two-echelon assembled-to-stock system consisting of several common components and end products. The results showed that when each type of component is shared by at least two end products, the safety stock levels are reduced requiring to be held at a sufficiently high service level. Catena et al. [28] proposed four models with commonality for calculating safety stock levels for subassemblies and manufacturing components under ATO and Make to Order (MTO) systems. Persona et al. [29] extended the study of Catena et al. [28] and applied the models in two different industries to prove the reduction in the safety stock levels. Like these works, there are many other studies focused on the effect of the component commonality on safety stock levels in modular production systems such as Gerchak and Henig [30]; Eynan and Rosenblatt [31]; Fisher et al. [32]; Cheung [23].

The main contribution of this work is the proposal of a model that includes Group Technology philosophy (GT) for the computation of safety stock levels in modular production systems. This inclusion extends the previous approaches that only considered component commonality. The mathematical model is tested through the simulation of three years of operation of two modular product systems. For each system, we calculated and compared the safety stock levels for two scenarios: (1) under the only presence of component commonality and (2) under the presence of both component commonality and GT. These scenarios are used to compare the performance of the mathematical model proposed with the traditional model. The results show a reduction in the safety stock levels without affecting the customer service levels (CSL).

The remainder of the paper is organized as follows. Section 2 shows the development of the proposed model. In Section 3 the simulation results are presented. Section 4 discusses the main implications of the model. Finally, Section 5 presents the conclusions and suggestions for future research.

\section{Mathematical Model}

According to Mikkola [6], the structure of a modular product is divided into four levels of complexity: system, subsystem, modules, and components. However, this structure is determined mainly by organizations considering their production approaches and the intended application of the products. This study divides the modular product into three levels of complexity: system, modules, and components.

A modular products system assumes the existence of

(i) $m$ end products with indexes $l=1,2, \ldots, m$;

(ii) $n$ modules with indexes $j=1,2, \ldots, n$;

(iii) $c$ components with indexes $i=1,2, \ldots, c$.

The number of components $i$ required to build one module $j$ is denoted as $a_{i j}$; and the number of modules $j$ required to build one end product $l$ is denoted as $b_{j l}$. Figure 1 shows this configuration and the matrices of composition of modules and components.

2.1. Preliminary Analysis. The structure of a modular products system supports managers in determining stock levels, because it allows them to know exactly the number of modules and components they need in an end product. In reality, all manufacturers operate with an investment in inventories, even those organizations that employ the Justin-Time strategy. These inventories consist of raw material, work in process, products from a reverse logistic system, subassemblies, and end products. All of them are necessary for very specific reasons that, taken together, facilitate efficient performance in organizations. In the ideal case, where a manufacturing system operates in a purely deterministic environment, the forecast demand is not necessary. However, in actual practice, this does not happen; there is always uncertainty in the environment and sudden changes in the customers behavior causing inaccurate forecasts, regardless of the forecasting method used.

It is well known that organizations turn to the preparation of forecasts to determine the future demand for their products. With these forecasts, they adjust their resources and production capacities in order to meet these demands. Because forecast is only approximations, the managers must always take into account a forecast value and a forecast 


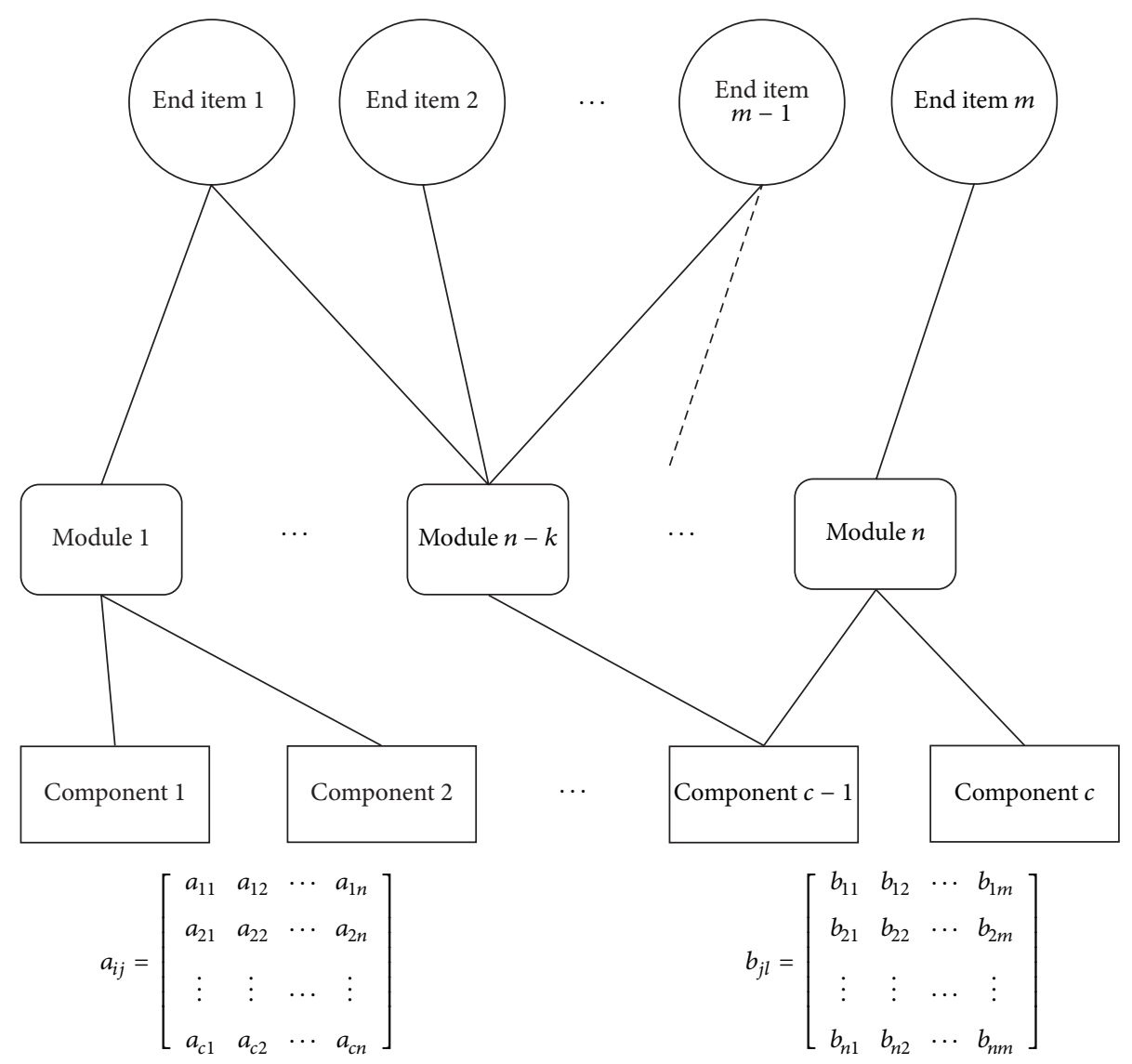

FIGURE 1: General structure of a modular products system and its matrices of composition.

error as metrics to determine the stocks levels. Therefore, to meet the real demand for a modular product over a period of time $t$, managers consider a deterministic amount and a random amount of inventory. As a consequence of the random component, safety stocks become necessary in an organization. Safety stocks are inventory that remain to meet the demand that exceeds the forecast in a period of time t. These stocks avoid stock-out costs and lost sales. For an organization, it is important to maintain optimal safety stock levels, because they also generate costs to keep them in the warehouse. It is harmful to have excess inventory when new competing products are introduced because the available inventory becomes obsolete.

In an environment of modular production, where the demand of a product in a period of time $t$ is bigger than forecast demand, the forecast error can be cover by the safety stock as follows:

$$
D_{t}=\omega \mu+\mathrm{SS},
$$

where

$D_{t}$ is demand of the period $t$;

$\omega$ is unit of time (days, weeks, and months) of the period $t$;

$\mu$ is the average of the forecasted demand;

SS is safety stock.
Assuming that the demand $D_{t}$ is normally distributed with mean $\mu$ and a variance $\operatorname{var}\left[D_{t}\right]$, by definition of the normal standard distribution and its inverse, the following expression is obtained:

$$
D_{t}=\omega \mu+k \sigma \sqrt{L} \text {. }
$$

Therefore, the safety stock is defined by the next expression:

$$
\mathrm{SS}=k \sigma \sqrt{L}
$$

where

SS is safety stock;

$k$ is the safety factor that determines the probability that the real demand of a product is less than or equal to the forecasted demand plus the safety stock;

$L$ is lead-time;

$\sigma$ is standard deviation of the demand.

Indeed, the safety stock SS represents the stock-out in the stock cycle during the period of time between the processes of placing and receiving an order; that is,

$$
\mathrm{ROP}=L \mu+\mathrm{SS}
$$


where ROP is the reorder point and $\mu$ is the mean of the demand through the planning horizon.

Expression (3) determines the safety stock for an end product, which assumes independence in its demand and does not consider the presence of component commonality. This expression only considers as key metrics the standard deviation and a safety factor $k$ to ensure a certain CSL.

However, in practice, organizations adopt different strategies to reduce the safety stock levels to maintain low costs; to start to reduce them, an organization needs to create an aggregate inventory; this consists in centralizing inventories in a single warehouse, instead of having different storage points. The aggregate inventories generate savings in inventory holding costs; the process of building part families by GT is facilitated and allows the efficient use of the component commonality.

An organization that offers a wide variety of modular products as customized products must maintain an aggregation in inventories. Now, if this organization seeks to reduce the safety stock levels, in addition to this aggregation, it also must consider the application of the component commonality. Then, in this case, Expression (3) can be generalized considering the distribution of the aggregate inventory, which has a normal distribution with an aggregate demand $d^{\prime}$, a variance $\operatorname{var}\left[d^{\prime}\right]$, and a standard deviation $\sigma^{\prime}$, as follows in expressions (5). One has

$$
\begin{aligned}
d^{\prime} & =\sum_{l=1}^{m} d_{l}, \\
\operatorname{var}\left[d^{\prime}\right] & =\sum_{l=1}^{m} \sigma_{l}^{2}+2 \sum_{l<z} \operatorname{cov}_{l z}=\sum_{l=1}^{m} \sigma_{l}^{2}+2 \sum_{l<z} \rho_{l z} \sigma_{l} \sigma_{z}, \\
\sigma^{\prime} & =\sqrt{\operatorname{var}\left[d^{\prime}\right]}=\sqrt{\sum_{l=1}^{m} \sigma_{l}^{2}+2 \sum_{l<z} \rho_{l z} \sigma_{l} \sigma_{z},}
\end{aligned}
$$

where $\rho_{l z}$ is the Pearson correlation coefficient between the final products $l$ and $z$, while the sum of the standard deviations represents those deviations where component commonality exists. From expressions (3) and (5), the safety stock for each final product $l$ into an aggregate inventory of modular products with component commonality can be determined based on the next expression:

$$
\mathrm{SS}_{l}=k \sigma_{\alpha} \sqrt{L_{l}}=k \sqrt{\sum_{l=1}^{m} \sigma_{l}^{2}+2 \sum_{l<z} \rho_{l z} \sigma_{l} \sigma_{z}} \sqrt{L_{l}} .
$$

When the demands are independent $\left(\rho_{l z}=0\right)$ between all end products, expression (6) is simplified as follows:

$$
\mathrm{SS}_{l}=k \sqrt{\sum_{l=1}^{m} \sigma_{l}^{2}} \sqrt{L_{l}} .
$$

Expressions (6) and (7) determine the safety stock levels of end products with dependent and independent demands, respectively, considering the use of the aggregate inventories and the component commonality.

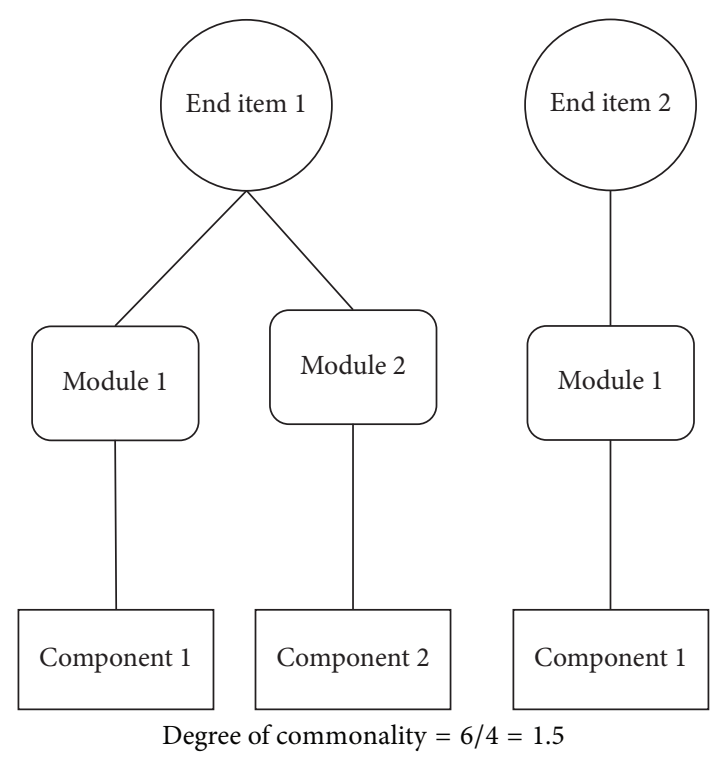

FIGURE 2: Degree of commonality in two simple modular products.

This preliminary analysis develops expressions (3)-(7) that already have been developed in previous literature. These expressions are presented in this paper because these are the basis to construct the proposed model.

2.2. Proposed Model. Under MTS and ATS production approaches, it is necessary to determine the safety stock levels for each component that exists in a modular products system, and expressions (6) and (7) are the basis for calculation.

To determine the safety stock of each component of a modular products system, we must consider the degree of commonality present in the system. According to Collier [24], the structure of the system determines the degree of commonality; this is defined as the total number of modules and components in the system divided by the total number of distinct modules and components. Figure 2 shows an example of how to calculate the degree of commonality of two modular products.

Considering the existence of modules and common components, expression (6) is adjusted to determine the safety stock levels of each component in the system; therefore, in each term of the expression, we consider the participation of components in modules and modules in end products. The expression developed is as follows:

$$
\begin{aligned}
& \mathrm{SS}_{i} \\
& =k \sqrt{\sum_{j=1}^{n} \sum_{l=1}^{m} a_{i j} b_{j l} \sigma_{l}^{2}+2 \sum_{j=1}^{n} \sum_{l=1}^{m-1} \sum_{z=2}^{m} a_{i j}^{2} b_{j l} b_{j z} \rho_{l z} \sigma_{l} \sigma_{z}} \sqrt{L_{i}} .
\end{aligned}
$$

When there is independence in demands between the end products, expression (8) is simplified as follows:

$$
\mathrm{SS}_{i}=k \sqrt{\sum_{j=1}^{n} \sum_{l=1}^{m} a_{i j} b_{j l} \sigma_{l}^{2}} \sqrt{L_{i}} .
$$


Expressions (8) and (9) have been developed in this paper for calculating safety stocks of the components of a modular products system with component commonality and with three levels of complexity. However, the proposed model also suggests the presence of a factor of substitution from the GT philosophy to reduce further the safety stock levels.

2.2.1. Factor of Substitution. The GT is a manufacturing philosophy that brings together the components with similar physical features (shape, size, and manufacturing processes) in part families to take advantages in the optimization of many processes such as lead times, setup times, processing times, labor operations, and reworks. From GT philosophy, we define a factor of substitution of a component $i$ as $f_{\text {si }}$, which considers a fraction of substitute components $r_{i}$ within the part family to which the component $i$ belongs, and by their similarities, the component $i$ can be replaced by them in case of stock-out. An example of substitutes components are two similar screws with different drives in the heads. It assume that this substitution does not affect or change the shape, function, costs, and physical and mechanical properties of the end product. The fraction $r_{i}$ is defined as follows:

$$
r_{i}=\frac{n_{i}}{\left(\left(\sum_{i=1}^{c} N_{i}-1\right) / C\right)},
$$

where

$r_{i}$ is fraction of substitution of the component $i$;

$n_{i}$ is amount of substitute components of the component $i$;

$N$ istotal components within the part family of the component $i$.

By using a basic mathematical model, the factor of substitution $f_{s i}$ decreases at a rate $r_{i}$ proportionally to the number of components $n_{i}$ existing within the part family. If $f_{s i}$ is the factor of substitution of a component $i$, then $f_{s i}$ varies at a rate $\Delta f_{s i}=r_{i} f_{s i}$ as much as the number of components $n_{i}$ increases or decreases; in other words, for every unit that increases the value $n_{i}$ in the system, $f_{s i}$ takes a proportional value to this change. Hence

$$
\Delta f_{s i}=\left(-r_{i} f_{s i}\right) \Delta n_{i}
$$

In differential equation form,

$$
\frac{d f_{s i}}{d n_{i}}=-r_{i} f_{s i}=\left[\frac{-n_{i}}{\left(\left(\sum_{i=1}^{c} N_{i}-1\right) / C\right)}\right] f_{s i} .
$$

For any value of $r_{i}$, the solution of the differential equation is presented in next expression:

$$
f_{s i}=e^{-n_{i}^{2} / 2\left[\left(\sum_{i=1}^{c} N_{i}-1\right) / C\right]} .
$$

Figure 3 shows some patterns of the factor of substitution under different sizes of part families. In this figure we can observe that, in a scenario with absence of substitute components $\left(n_{i}=0\right)$, the factor of substitution takes a maximum value $\left(f_{s i}=1\right)$, and while increasing the value of $n_{i}$, the value of $f_{s i}$ approximates to zero.

2.2.2. Integration of the Proposed Model. Expressions (8) and (9) determine the safety stock levels for the components of a modular products system with commonality and under an aggregate inventory. However, these levels can be reduced including the factor of substitution in expression (8) as follows:

$$
\mathrm{SS}_{i}=e^{-n_{i}^{2} / 2\left[\left(\sum_{i=1}^{c} N_{i}-1\right) / C\right]} k \sqrt{\sum_{j=1}^{n} \sum_{l=1}^{m} a_{i j} b_{j l} \sigma_{l}^{2}+2 \sum_{j=1}^{n} \sum_{l=1}^{m-1} \sum_{z=2}^{m} a_{i j}^{2} b_{j l} b_{j z} \rho_{l z} \sigma_{l} \sigma_{z}} \sqrt{L_{i}} .
$$

When demands are independent, expression (14) is simplified as follows:

$$
\mathrm{SS}_{i}=e^{-n_{i}^{2} / 2\left[\left(\sum_{i=1}^{c} N_{i}-1\right) / C\right]} k \sqrt{\sum_{j=1}^{n} \sum_{l=1}^{m} a_{i j} b_{j l} \sigma_{l}^{2}} \sqrt{L_{i}} .
$$

Expressions (14) and (15) are the result of joining the component commonality with the GT philosophy for reducing the safety stock levels. We can see that when $f_{s i}$ takes its maximum value, expression (14) becomes expression (8); while increasing the value by $n_{i}$, the safety stock $S_{i}$ is reduced.

The basic principle of the proposed model consists in reducing safety stock levels in modular production systems through an exponential smoothing. This reduction is in function of the degree of commonality and of the amount of components $N_{i}$ and $n_{i}$ in the part families. The reduction is given due to the possibility of sharing cyclical and safety stocks between substitute components. Thus, this strategy allows eliminating the negative effect in case of stock-outs.

To evaluate the proposed model, Section 3 presents two applications based on simulation regarding the operation of two different modular products systems.

\section{Application and Results}

The proposed model is evaluated through two applications based on the simulation of three years of operation of two modular products systems, where each system has its own structure and its own degree of component commonality. The 


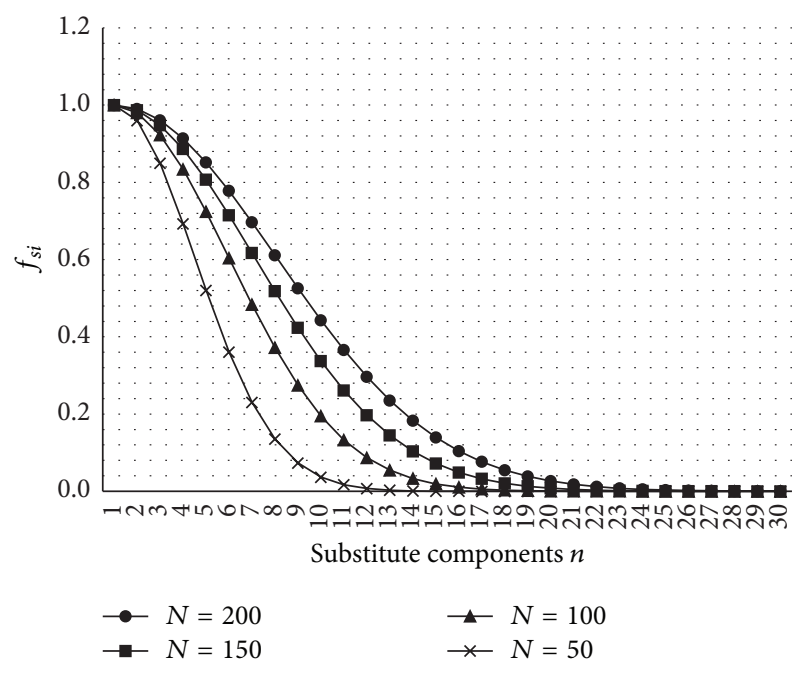

FIGURE 3: Functions for the factor of substitution.

analysis of each application makes the comparison of performance between safety stocks calculated for two scenarios: (1) under the only presence of component commonality and (2) with the presence of component commonality and the factor of substitution from GT philosophy.

The simulations have been developed using $\mathrm{C}++$ language, where after generating demands for end products, the safety stocks, reorder points, initial and final inventories, components used, and stock-outs for each component are calculated. The results for each scenario in both applications have been derived from thirty simulation runs. Figure 4 shows the general simulation process.

To make the applications simple, we suppose the following conditions held:

(1) A continuous review (Q, R) policy is used to determine the safety stock levels.

(2) There is one period of lead-time for first application.

(3) There are two periods of lead-time for second application.

(4) In each period simulated, demand for end products $l$ follows a normal distribution, with mean $\mu_{l}$ and standard deviation $\sigma_{l}$.

(5) For each case, it assumes aggregate inventories for production.

(6) The CSL is $90 \%(k=1.28)$.

(7) There is a buffer of enough substitute components to meet the demand in case of stock-outs.

(8) The substitution of components does not affect or change the shape, function, costs, and physical and mechanical properties of the end product.

(9) Each component analyzed belongs to a different part family.

3.1. Application One. This application simulates and analyzes two modular products (EP1 and EP2) of an enterprise that
TABLE 1: Initial inventories and quantity orders.

\begin{tabular}{lcccc}
\hline$c_{i}$ & 1 & 2 & 3 & 4 \\
\hline I. Initial & 10000 & 9500 & 10500 & 9000 \\
$Q_{i}$ & 7000 & 8000 & 7000 & 4000 \\
\hline
\end{tabular}

TABLE 2: Safety stock levels and reorder points.

\begin{tabular}{lcccc}
\hline$c_{i}$ & 1 & 2 & 3 & 4 \\
\hline $\mathrm{SS}_{i}$ & 185 & 212 & 185 & 154 \\
$\mathrm{ROP}_{i}$ & 1985 & 2712 & 1985 & 1254 \\
\hline
\end{tabular}

offers a high variety of different modular products to its customers. To manufacture all its products, the enterprise applies GT philosophy to arrange its components in part families. The two products analyzed are assembled from 3 modules and 4 components as shown in Figure 5. The structure of these two products has a degree of commonality of 1.7.

We suppose that the demands of these two end products are independent and normally distributed with means $\mu_{\mathrm{EP} 1}=$ 700 and $\mu_{\mathrm{EP} 2}=1100$, standard deviations $\sigma_{\mathrm{EP} 1}=80$ and $\sigma_{\mathrm{EP} 2}=120$. Table 1 shows the initial inventories and order quantities used for the two scenarios analyzed.

Case 1 (safety stocks with commonality). Based on the structure of Figure 4 and considering that the system handles aggregation in inventories with only component commonality, the safety stock for each component is determined by applying expression (9). Table 2 shows the calculated values for safety stocks and reorder points.

The results of the thirty simulation runs for this case are shown in Table 3. This table shows that five stockouts occurred in five simulation runs, generating a stockout average equal to 1 . The average inventories for each component also are showed.

Case 2 (safety stocks with commonality and factor of substitution). In this case, we suppose that each component $i$ of the two modular products analyzed belongs to a part family, the experiment assumes that each part family has its own total number of components $N_{i}$ with $n_{i}$ substitute components for the component $i$, and each substitute component has a large buffer to meet any demand. Table 4 shows the details with respect to the composition of the part families of each component $i$ of the system analyzed.

For an organization, obtaining the data in Table 4 is not a difficult task; they can be obtained through the construction of part families and identifying the substitute components for each member of the families. Once this information is structured, it can be used to calculate the safety stock levels for each component.

Given the information in Table 4, safety stock for each component of the system is determined using the expression (15), which considers the aggregation in inventories, existence of component commonality, independent demands, and the 


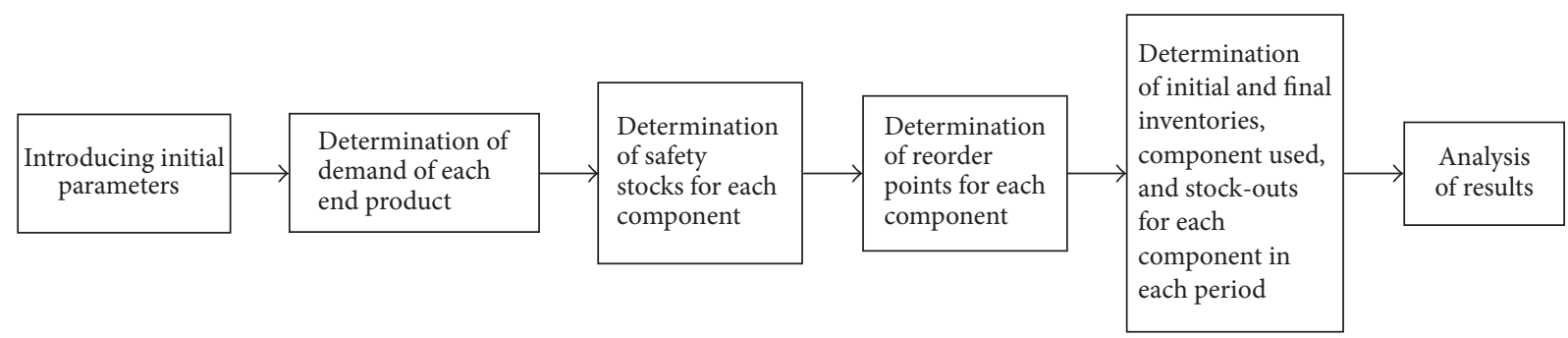

FIGURE 4: Simulation process.

TABLE 3: Results of the simulation: Case 1.

\begin{tabular}{lcccccc}
\hline & \multicolumn{2}{c}{ Stock-outs } & & \multicolumn{3}{c}{ Average inventories } \\
Amount of stock-outs & Runs with stock-outs & Average of stock-outs & $c 1$ & $c 2$ & $c 3$ & $c 4$ \\
\hline 5 & 5 & 1 & 5563 & 6847 & 5804 & 3701 \\
\hline
\end{tabular}

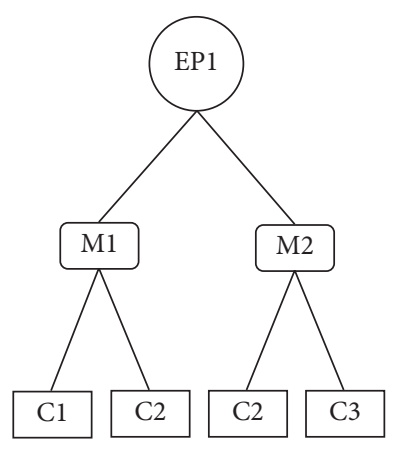

$a_{i j}=\left[\begin{array}{lll}1 & 0 & 0 \\ 1 & 1 & 0 \\ 0 & 1 & 1 \\ 0 & 0 & 1\end{array}\right]$

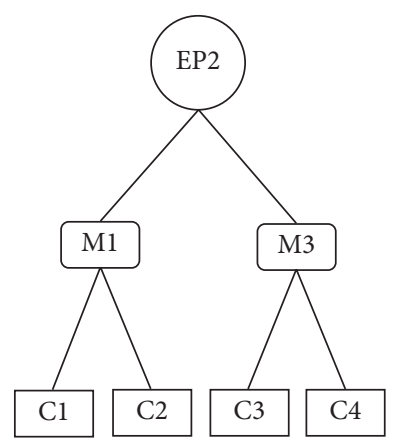

$b_{j l}=\left[\begin{array}{ll}1 & 1 \\ 1 & 0 \\ 0 & 1\end{array}\right]$

FIgURE 5: A system of two modular products and its matrices of composition.

TABle 4: Part families composition.

\begin{tabular}{lcccc}
\hline$c_{i}$ & 1 & 2 & 3 & 4 \\
\hline$N_{i}$ & 25 & 30 & 45 & 60 \\
$n_{i}$ & 3 & 6 & 4 & 6 \\
\hline
\end{tabular}

TABLE 5: Safety stock levels and reorder points.

\begin{tabular}{lcccc}
\hline$c_{i}$ & 1 & 2 & 3 & 4 \\
\hline $\mathrm{SS}_{i}$ & 166 & 135 & 152 & 98 \\
$\mathrm{ROP}_{i}$ & 1966 & 2635 & 1952 & 1198 \\
\hline
\end{tabular}

factor of substitution. Table 5 shows the calculated values for safety stocks and reorder points.

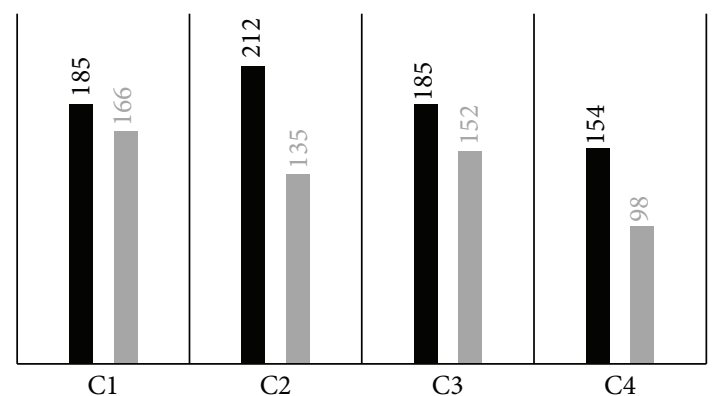

- Case 1

Case 2

FIGURE 6: Safety stock levels for each component in both scenarios.

The results of the thirty simulation runs for this case are shown in Table 6. This table shows that eight stockouts occurred in six simulation runs, generating a stockout average equal to 1.3. The average inventories for each component also are showed.

3.1.1. A Performance Comparison between the Two Cases. Tables 3 and 6 show the results of each case; these tables show that there are a greater number of stock-outs and lower average inventories in Case 2 as a result of reducing safety stock levels. However, the experiment involves the possibility of using substitute components to meet this demand, while stock-outs in Case 1 become in shortage costs. Figure 6 shows the difference between safety stock levels calculated in each case for each component in the system. An example of one simulation run for both cases is shown in Table 7 .

3.2. Application Two. Similar to the previous application, this application analyzes and simulates a system of modular products composed of five end products EP1, EP2,..., EP5, which are assembled from five modules and five components as shown in Figure 7. The structure has a degree of commonality 
TABLE 6: Results of the simulation: Case 2.

\begin{tabular}{lcccccc}
\hline & \multicolumn{2}{c}{ Stock-outs } & & \multicolumn{3}{c}{ Average inventories } \\
Amount of stock-outs & Runs with stock-outs & Average of stock-outs & $c 1$ & $c 2$ & $c 3$ & $c 4$ \\
\hline 8 & 6 & 1.3 & 5542 & 6795 & 5785 & 3648 \\
\hline
\end{tabular}
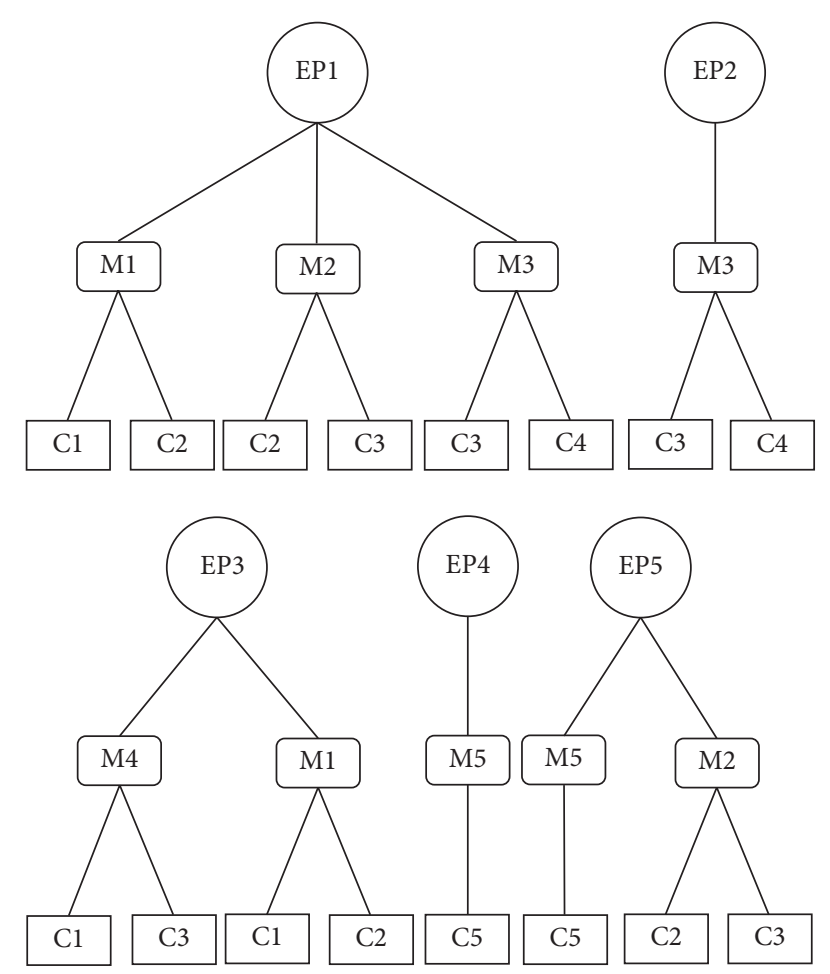

$$
a_{i j}=\left[\begin{array}{ccccc}
1 & 0 & 0 & 1 & 0 \\
1 & 1 & 0 & 0 & 0 \\
0 & 1 & 1 & 1 & 0 \\
0 & 0 & 1 & 0 & 0 \\
0 & 0 & 0 & 0 & 1
\end{array}\right] \quad b_{j l}=\left[\begin{array}{ccccc}
1 & 0 & 1 & 0 & 0 \\
1 & 0 & 0 & 0 & 1 \\
1 & 1 & 0 & 0 & 0 \\
0 & 0 & 1 & 0 & 0 \\
0 & 0 & 0 & 1 & 1
\end{array}\right]
$$

FIGURE 7: A system of five modular products and its matrices of composition.

of 2.5. The system uses the ATO strategy to meet the needs of its customers.

For this modular products system, we suppose that the demands of the end products are dependent. Table 8 shows the initial inventories and the order quantities of each component of the system, whereas Table 9 shows the means of the demands, the standard deviations, and the correlation coefficients of the end products. The information of both Tables 8 and 9 are used for the two cases analyzed.

Case 1 (safety stocks with commonality). In an environment where there are dependent demands between end products, determining safety stocks of each component of the system is performed by applying expression (8). Table 10 shows the calculated values for safety stocks as well as reorder points for each component.
The results of the thirty simulation runs for this case are shown in Table 11. This table shows that eight stockouts occurred in eight simulation runs, generating a stockout average equal to 1 . The average inventories for each component also are showed.

Case 2 (safety stocks with commonality and factor of substitution). Similar to Case 2 of the application 1, each component $i$ of the modular products system belongs to a part family. Each part family has its own total number of components $N_{i}$ with a number $n_{i}$ of substitute components by the component $i$, and each substitute component has a large buffer to meet any demand. Table 12 shows the details regarding the composition of the part families of each component $i$ of the system analyzed.

For this case, the safety stocks are calculated using expression (14), because this expression considers the existence of aggregation in inventories, commonality, dependent demands, and factor of substitution. Table 13 shows the calculated values of the safety stocks and reorder points for each component of the system.

The results of the thirty simulation runs for this case are shown in Table 14. This table shows that forty-four stock-outs occurred in twenty-six simulation runs, generating a stockout average equal to 1.7. The average inventories for each component also are showed.

3.2.1. A Performance Comparison between the Two Cases. Tables 11 and 14 show the results of each case; these tables show that there are a greater number of stock-outs and lower average inventories in Case 2 as a result of reducing safety stock levels. Similar to that in application one, the experiment involves the possibility of using substitute components to meet this demand, while stock-outs in Case 1 become in shortage costs. Figure 8 shows the difference between safety stock levels calculated in each case for each component in the system. An example of one simulation run for both cases is shown in Table 15.

\section{Discussion}

Currently, uncertainty in demand and variability in consumer behavior hinder decision-making concerning the determination of the optimal safety stock levels. As a result, an organization requires a sufficient level of these inventories to ensure a high CSL. Greater safety stock levels represent higher costs. Of course, safety stocks are not the only factor that can negatively affect the CSL; there are other factors that also affect it directly, such as product quality, after-sales 


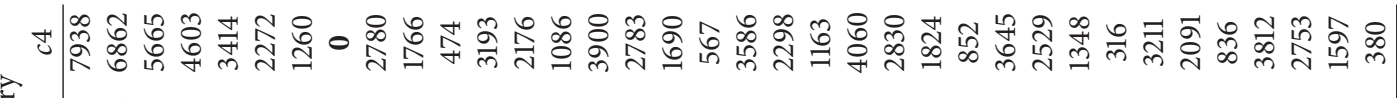

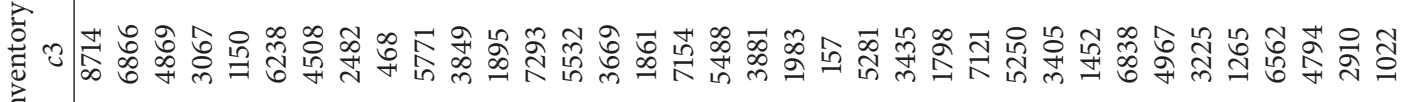

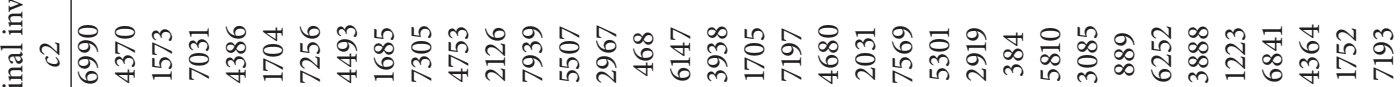

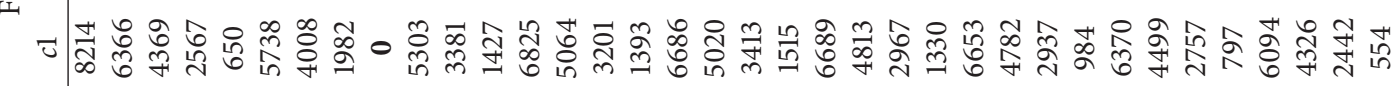

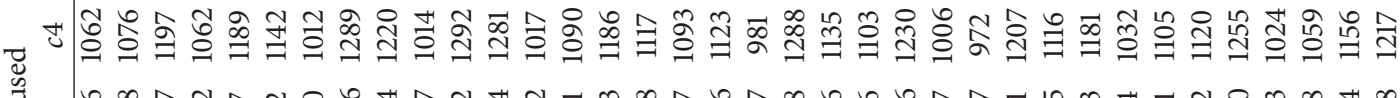
$\sim$

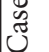

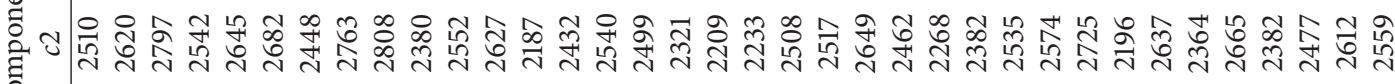

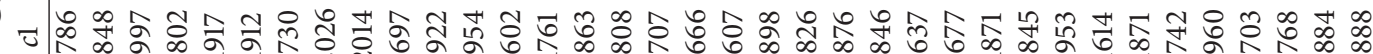

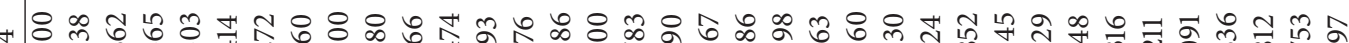

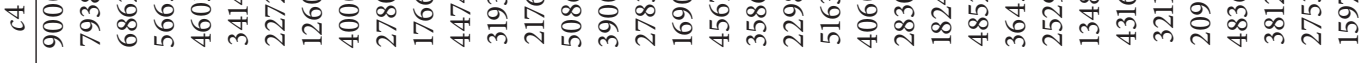

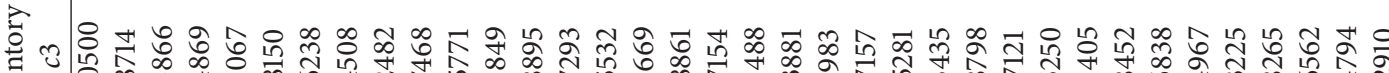

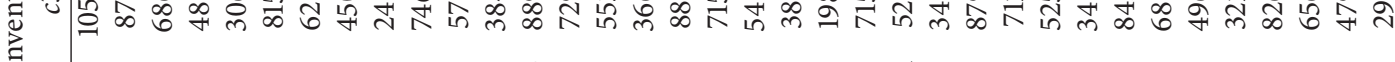

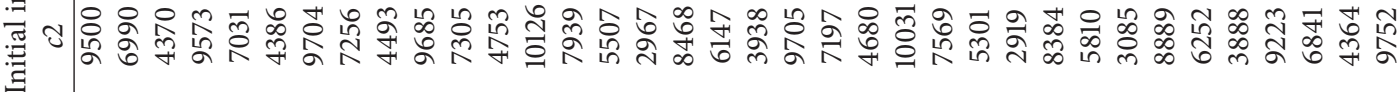

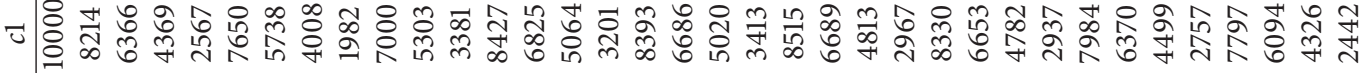
겅유.

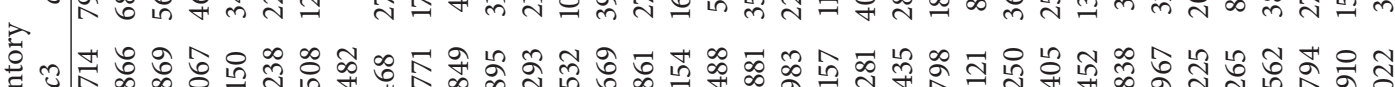

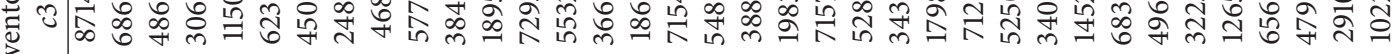

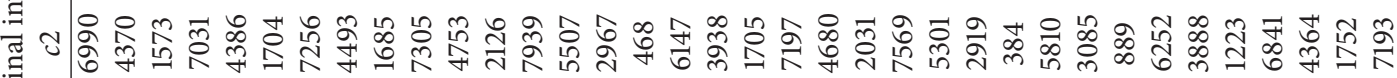

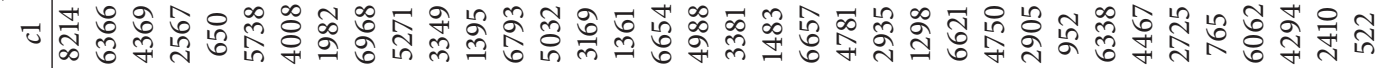

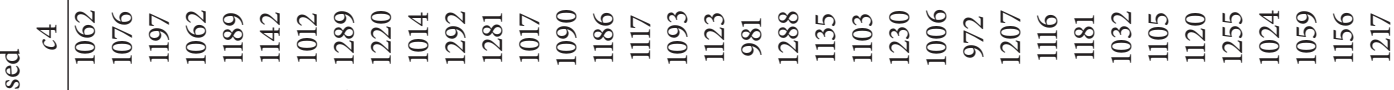

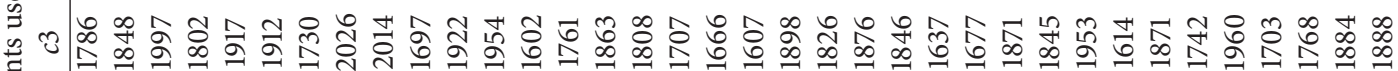

范

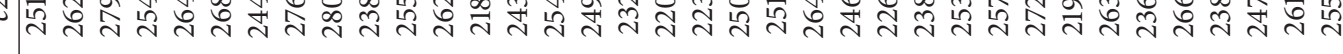

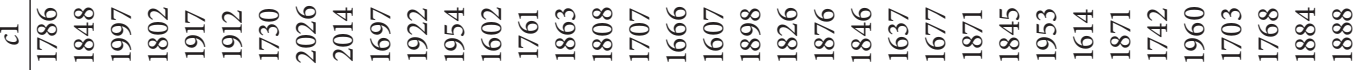

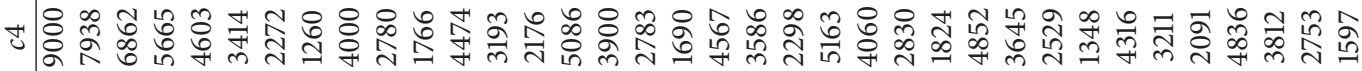

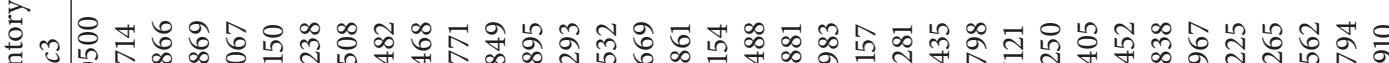

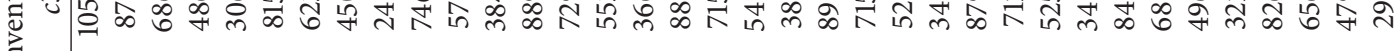

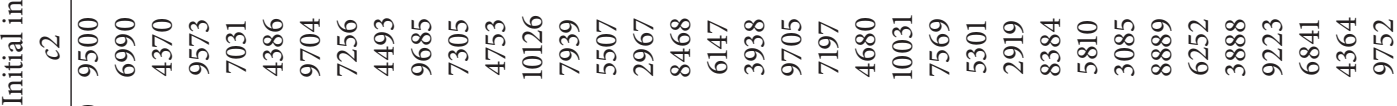

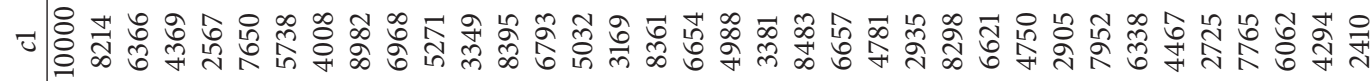

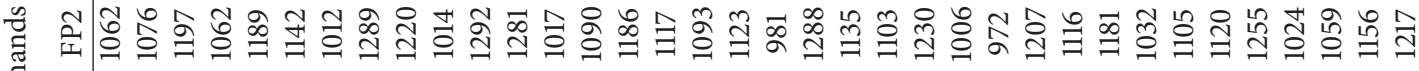
I

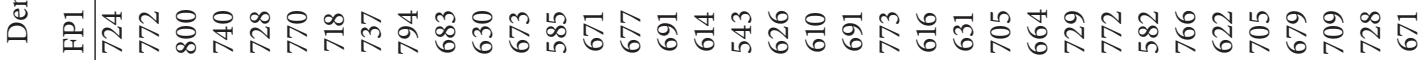
ㅎํㄹ 
TABLE 8: Initial inventories and quantity orders.

\begin{tabular}{lccccc}
\hline$c_{i}$ & 1 & 2 & 3 & 4 & 5 \\
\hline I. Initial & 10000 & 10000 & 10000 & 10000 & 10000 \\
$Q_{i}$ & 6000 & 12000 & 14000 & 4000 & 4000 \\
\hline
\end{tabular}

TABLE 9: Correlation coefficients, means of demands, and standard deviations.

\begin{tabular}{lccccc}
\hline$\rho_{l z}$ & EP1 & EP2 & EP3 & EP4 & EP5 \\
\hline EP1 & - & 0.72 & 0.61 & 0.75 & 0.8 \\
EP2 & 0.72 & - & 0.55 & 0.66 & 0.32 \\
EP3 & 0.61 & 0.55 & - & - & 0.91 \\
EP4 & 0.75 & 0.66 & 0.32 & 0.44 & 0.43 \\
EP5 & 0.8 & 0.91 & 0.53 & 600 & 450 \\
\hline$\mu_{i}$ & 550 & 450 & 950 & 105 & 75 \\
\hline$\sigma_{i}$ & 80 & 75 & 95 & & \\
\hline
\end{tabular}

TABLE 10: Safety stocks and reorder points.

\begin{tabular}{lccccc}
\hline$c_{i}$ & 1 & 2 & 3 & 4 & 5 \\
\hline $\mathrm{SS}_{i}$ & 333 & 390 & 411 & 261 & 278 \\
$\mathrm{ROP}_{i}$ & 4033 & 4790 & 5711 & 2261 & 2378 \\
\hline
\end{tabular}

TABLE 11: Results of the simulation; Case 1.

\begin{tabular}{|c|c|c|c|c|c|c|c|}
\hline \multicolumn{3}{|c|}{ Stock-outs } & \multicolumn{5}{|c|}{ Average inventories } \\
\hline Amount of stock-outs & Runs with stock-outs & Average of stock-outs & $c 1$ & $c 2$ & $c 3$ & $c 4$ & $c 5$ \\
\hline 8 & 8 & 1 & 5375 & 8452 & 10024 & 3951 & 3978 \\
\hline
\end{tabular}

TABLE 12: Part families composition.

\begin{tabular}{llcccc}
\hline$c_{i}$ & 1 & 2 & 3 & 4 & 5 \\
\hline$N_{i}$ & 9 & 15 & 18 & 9 & 13 \\
$n_{i}$ & 4 & 7 & 5 & 5 & 6 \\
\hline
\end{tabular}

TABLE 13: Safety stocks and reorder points.

\begin{tabular}{lccccc}
\hline$c_{i}$ & 1 & 2 & 3 & 4 & 5 \\
\hline $\mathrm{SS}_{i}$ & 176 & 55 & 152 & 97 & 66 \\
$\mathrm{ROP}_{i}$ & 3876 & 4455 & 5452 & 2097 & 2166 \\
\hline
\end{tabular}

TABLE 14: Results of the simulation: Case 2.

\begin{tabular}{lccccccc}
\hline & \multicolumn{2}{c}{ Stock-outs } & \multicolumn{4}{c}{ Average inventories } \\
Amount of stock-outs & Runs with stock-outs & Average of stock-outs & $c 1$ & $c 2$ & $c 3$ & $c 4$ & $c 5$ \\
\hline 44 & 26 & 1.7 & 5239 & 8169 & 9728 & 3821 & 3820 \\
\hline
\end{tabular}

services, and production capacity. Integrating all these factors to ensure a high CSL is an important area for research.

The proposed model in this paper solves the problem of reducing safety stock levels without affecting CSL in organizations that employ modular production as a strategy to offer a wide variety of products. The model suggests that the safety stock level for a component belonging to a modular products system can be reduced through exploiting the benefits of the aggregation of inventories, standardization of components, the degree of commonality, and the GT 


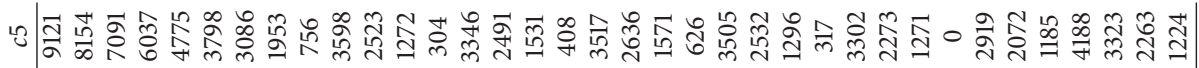

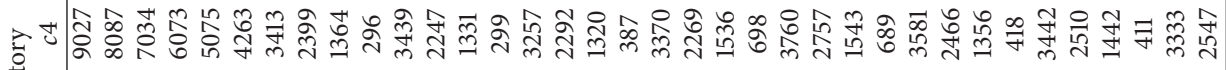

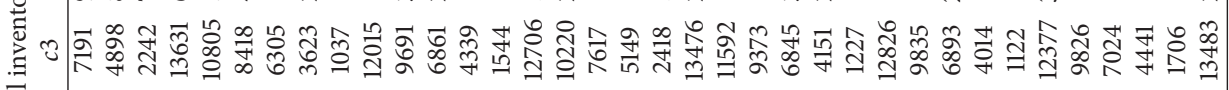

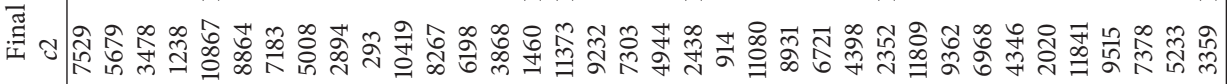

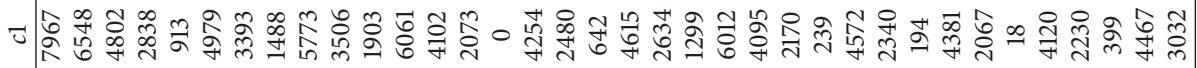

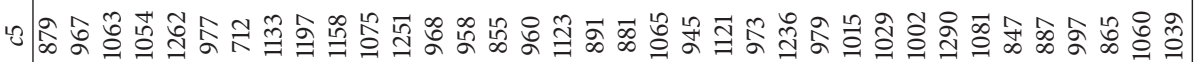

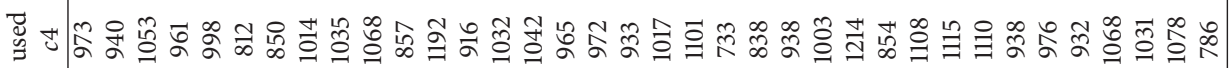

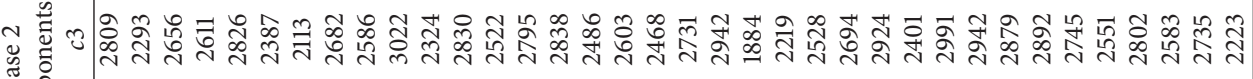

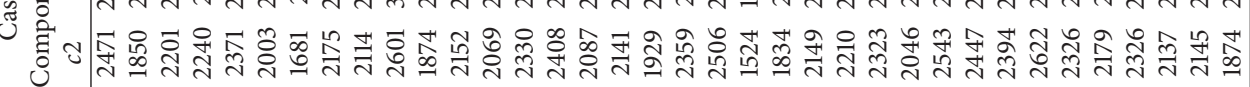

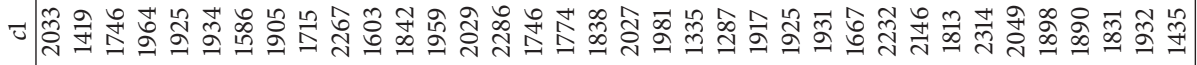

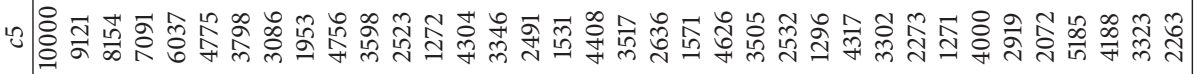

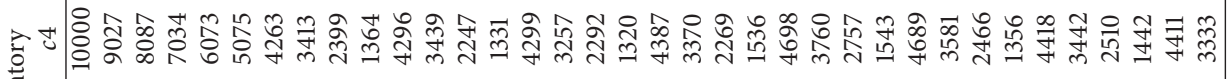

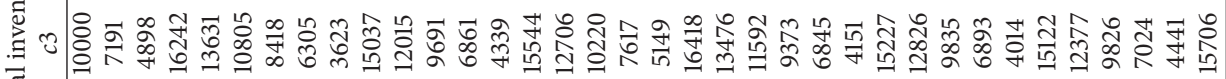

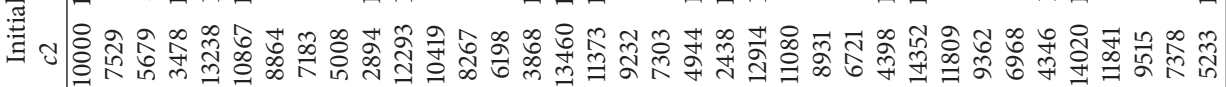

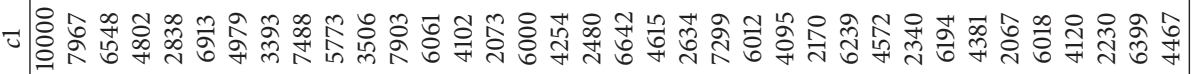

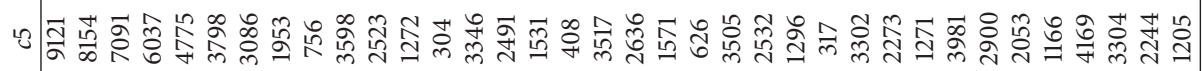

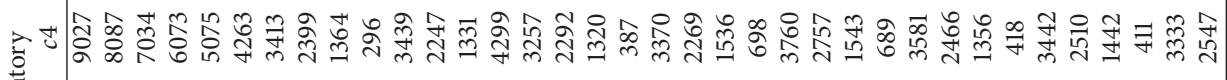

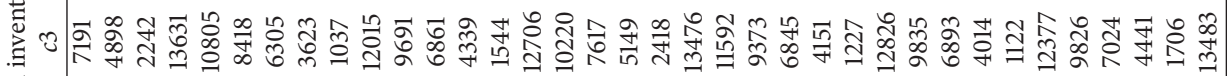

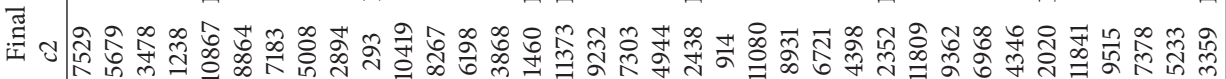

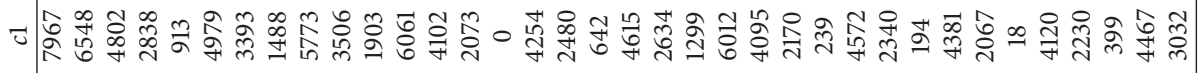

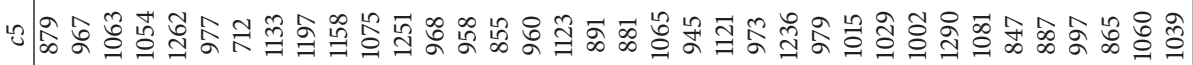

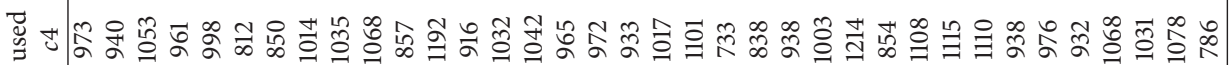

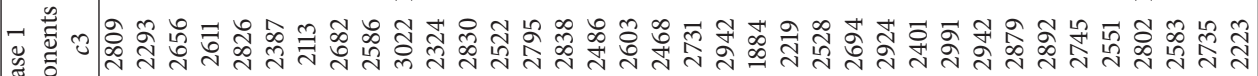

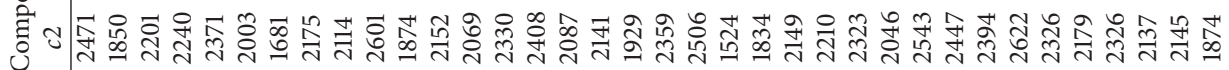

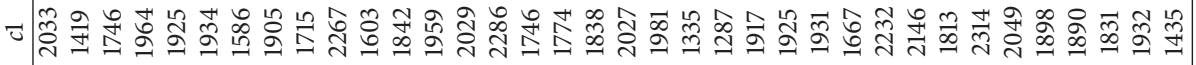

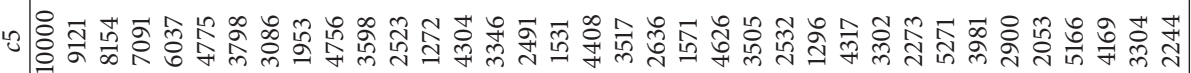

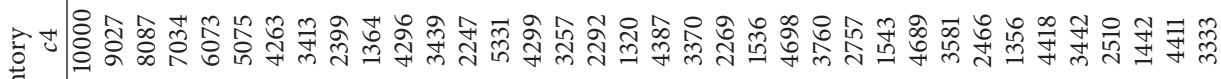

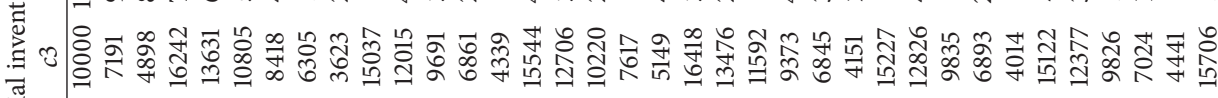

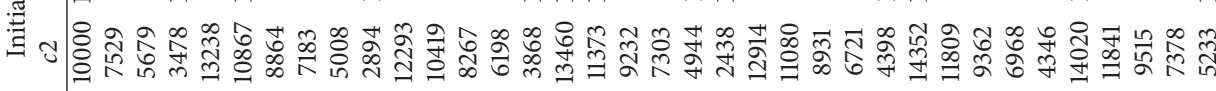

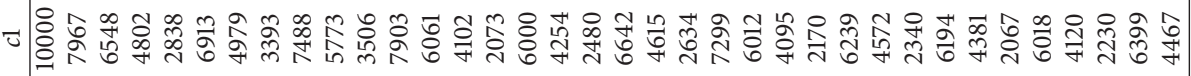
㖟 


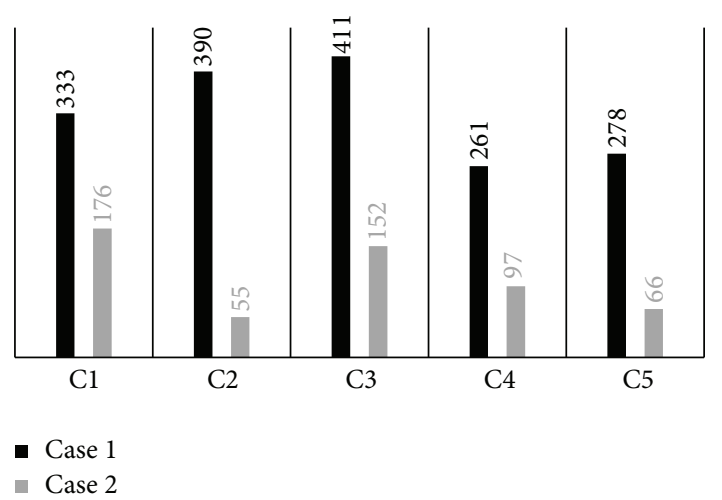

FIGURE 8: Safety stock levels for each component in both scenarios.

philosophy. The model assumes that the negative effect of increasing the amount of stock-outs can be eliminated when using substitute components to meet demands.

The model facilitates basic economies of substitution, such as costs reduction and inventory reduction as well as reduction in system complexity. For best performance, the model requires a high degree of integration between all areas of the organization, because that forces organizations to adopt the best strategies to achieve a proper standardization and to define an efficient methodology for the construction of part families.

\section{Conclusions and Suggestions for Future Research}

In this paper, we explored and quantified the positive effect of linking component commonality and GT philosophy on safety stock levels for organizations that employ modular production. Specifically, we achieved two objectives: (1) we showed an efficient way of reducing safety stock levels, and (2) we expanded knowledge regarding the positive relationship between component commonality and the GT philosophy.

The main contribution of this paper is the development of an efficient model for reducing safety stocks levels in modular production systems by linking component commonality with GT philosophy, thus creating a factor of substitution for components with great physical similarities. The factor of substitution constitutes an extension to the basic theory of quantitative models used for determining safety stock levels in organizations employing modular production. The model is a good option for companies whose holding costs are bigger than their shortage costs.

It is important to mention that, traditionally, researchers have developed mathematical models to try to determine the optimal safety stock levels for different strategies of production. They assumed that the demand that exists within the elapsed time period between when an order is made and when it is received follows a normal distribution. However, some studies have shown that the normal distribution is not the best representation of the demand behavior during a waiting time, but for ease of operation, a model that assumes a normal distribution represents the basis for other applications with higher requirements.

The proposed model is compared with the traditional method through a simulation study for two modular products systems with different degrees of commonality, where, for each component in both systems, we calculated the safety stocks, reorder points, initial and final inventories, and the usability of components. The result shows a reduction in safety stock levels allowing a high CSL.

For future research, the model can be tested using components belonging to the same part family and these can be substituted between them; also the model can be adjusted to different demand distributions to evaluate the performance. It is possible to supplement it with a study assessing the impact on total costs under different scenarios and different operational strategies. Finally, the model can be extended to products of more than three levels of complexity.

\section{Competing Interests}

The authors declare that they have no competing interests.

\section{References}

[1] Z. M. Bi and W. J. Zhang, "Modularity technology in manufacturing: taxonomy and issues," The International Journal of Advanced Manufacturing Technology, vol. 18, no. 5, pp. 381-390, 2001.

[2] K. Ramdas, "Managing product variety: an integrative review and research directions," Production and Operations Management, vol. 12, no. 1, pp. 79-101, 2003.

[3] C. Berry, H. Wang, and S. J. Hu, "Product architecting for personalization," Journal of Manufacturing Systems, vol. 32, no. 3, pp. 404-411, 2013.

[4] G. G. Rogers and L. Bottaci, "Modular production systems: a new manufacturing paradigm," Journal of Intelligent Manufacturing, vol. 8, no. 2, pp. 147-156, 1997.

[5] F. Salvador, C. Forza, and M. Rungtusanatham, "Modularity, product variety, production volume, and component sourcing: theorizing beyond generic prescriptions," Journal of Operations Management, vol. 20, no. 5, pp. 549-575, 2002.

[6] J. H. Mikkola, "Capturing the degree of modularity embedded in product architectures," Journal of Product Innovation Management, vol. 23, no. 2, pp. 128-146, 2006.

[7] A. J. Vakharia, D. A. Parmenter, and S. M. Sanchez, "The operating impact of parts commonality," Journal of Operations Management, vol. 14, no. 1, pp. 3-18, 1996.

[8] U. W. Thonemann and M. L. Brandeau, "Optimal commonality in component design," Operations Research, vol. 48, no. 1, pp. $1-19,2000$.

[9] N. Nagarur and A. Azeem, "Impact of commonality and flexibility on manufacturing performance: a simulation study," International Journal of Production Economics, vol. 60-61, pp. 125-134, 1999.

[10] Q. Tu, M. A. Vonderembse, and T. S. Ragu-Nathan, "Impact of time-based manufacturing practices on mass customization and value to customer," Journal of Operations Management, vol. 19, no. 2, pp. 201-217, 2001. 
[11] K. W. Lau Antonio, R. C. M. Yam, and E. Tang, “The impacts of product modularity on competitive capabilities and performance: an empirical study," International Journal of Production Economics, vol. 105, no. 1, pp. 1-20, 2007.

[12] A. K. W. Lau, "Critical success factors in managing modular production design: six company case studies in Hong Kong, China, and Singapore," Journal of Engineering and Technology Management, vol. 28, no. 3, pp. 168-183, 2011.

[13] R. Sanchez, "Modular architectures in the marketing process," Journal of Marketing, vol. 63, pp. 92-111, 1999.

[14] R. Sanchez and J. T. Mahoney, "Modularity, flexibility, and knowledge management in product and organization design," Strategic Management Journal, vol. 17, no. 2, pp. 63-76, 1996.

[15] B. J. Pine, "Making mass customization happen: strategies for the new competitive realities," Planning Review, vol. 21, no. 5, pp. 23-24, 1993.

[16] S. Ahmad, R. G. Schroeder, and D. N. Mallick, "The relationship among modularity, functional coordination, and mass customization: implications for competitiveness," European Journal of Innovation Management, vol. 13, no. 1, pp. 46-61, 2010.

[17] B. Berman, "Should your firm adopt a mass customization strategy?" Business Horizons, vol. 45, no. 4, pp. 51-60, 2002.

[18] G. Da Silveira, D. Borenstein, and F. S. Fogliatto, "Mass customization: literature review and research directions," International Journal of Production Economics, vol. 72, no. 1, pp. 1-13, 2001.

[19] K. R. Baker, "Safety stocks and component commonality," Journal of Operations Management, vol. 6, no. 1, pp. 13-22, 1985.

[20] Y. Gerchak and M. Henig, "An inventory model with component commonality," Operations Research Letters, vol. 5, no. 3, pp. 157-160, 1986.

[21] Y. Gerchak, M. J. Magazine, and B. A. Gamble, "Component commonality with service level requirements," Management Science, vol. 34, no. 6, pp. 753-760, 1988.

[22] K. van Donselaar and J. Wijngaard, "Commonality and safety stocks," Engineering Costs and Production Economics, vol. 12, no. 1-4, pp. 197-204, 1987.

[23] K. L. Cheung, "The effects of component commonality in an infinite horizon inventory model," Production Planning \& Control: The Management of Operations, vol. 13, no. 3, pp. 326333, 2002.

[24] D. A. Collier, "The measurement and operating benefits of component part commonality," Decision Sciences, vol. 12, no. 1, pp. 85-96, 1981.

[25] K. R. Baker, M. J. Magazine, and H. L. Nuttle, "The effect of commonality on safety stock in a simple inventory model," Management Science, vol. 32, no. 8, pp. 982-988, 1986.

[26] M. S. Hillier, "Using commonality as backup safety stock," European Journal of Operational Research, vol. 136, no. 2, pp. 353-365, 2002.

[27] E. K. P. Chew, L. H. Lee, and Y. L. Lau, "Component commonality in assembled-to-stock systems," IIE Transactions (Institute of Industrial Engineers), vol. 38, no. 3, pp. 239-251, 2006.

[28] M. Catena, E. Ferrari, R. Manzini, and A. Persona, "Quantitative models for evaluating safety stocks in case of modular products," in Proceedings of the in 17th International Conference of Production Research, Blacksburg, Va, USA, August 2003.

[29] A. Persona, D. Battini, R. Manzini, and A. Pareschi, "Optimal safety stock levels of subassemblies and manufacturing components," International Journal of Production Economics, vol. 110, no. 1-2, pp. 147-159, 2007.
[30] Y. Gerchak and M. Henig, "Component commonality in assemble-to-order systems: models and properties," Naval Research Logistics, vol. 36, no. 1, pp. 61-68, 1989.

[31] A. Eynan and M. J. Rosenblatt, "Component commonality effects on inventory costs," IIE Transactions, vol. 28, no. 2, pp. 93-104, 1996.

[32] M. Fisher, K. Ramdas, and K. Ulrich, "Component sharing in the management of product variety: a study of automotive braking systems," Management Science, vol. 45, no. 3, pp. 297315, 1999. 


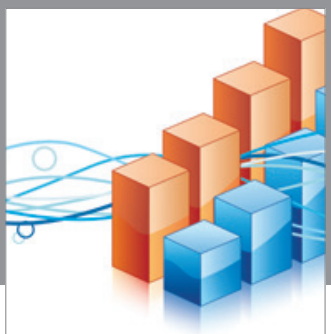

Advances in

Operations Research

vatem alat4

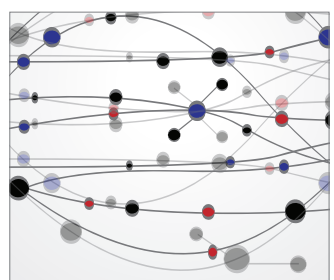

\section{The Scientific} World Journal
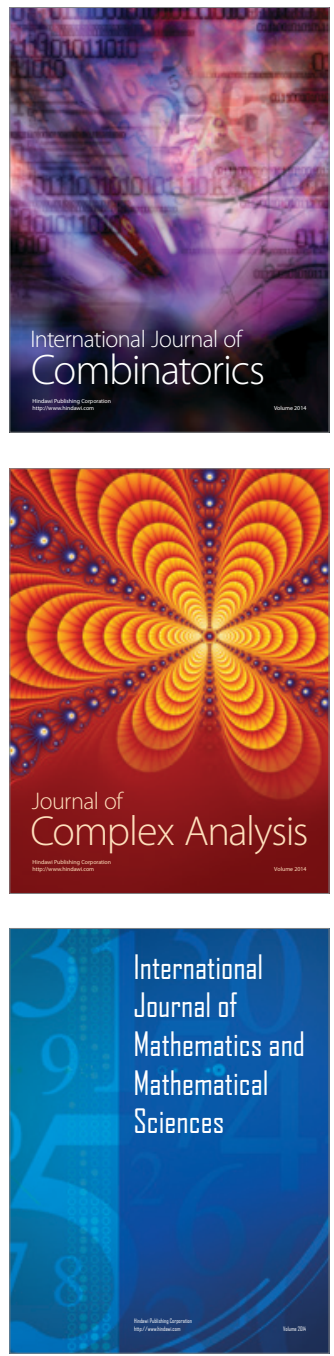
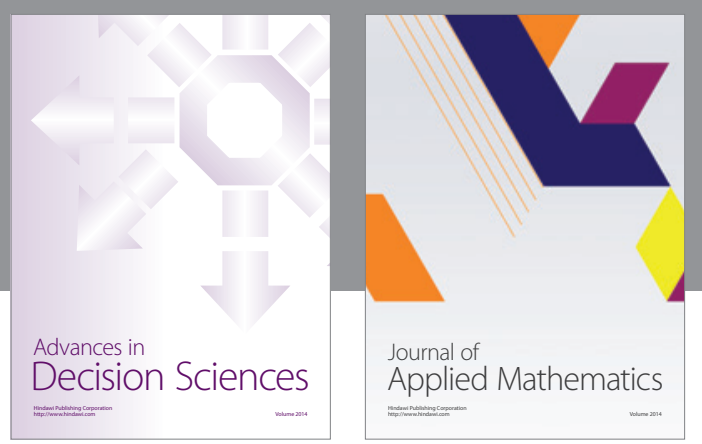

Algebra

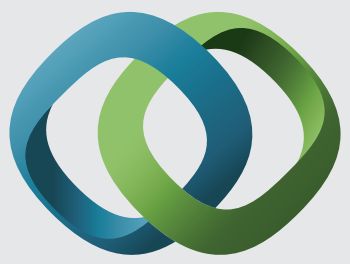

\section{Hindawi}

Submit your manuscripts at

http://www.hindawi.com
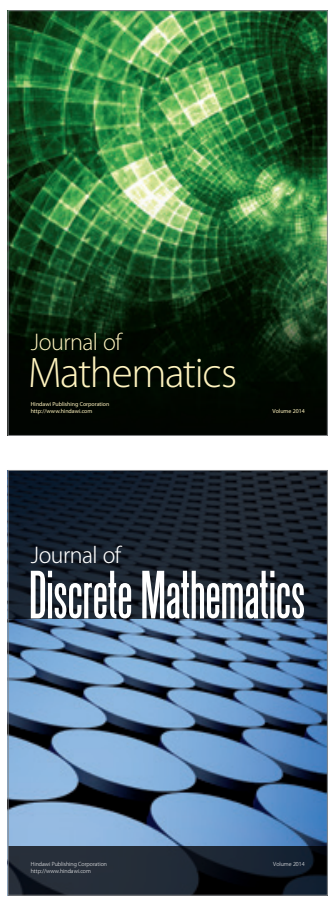

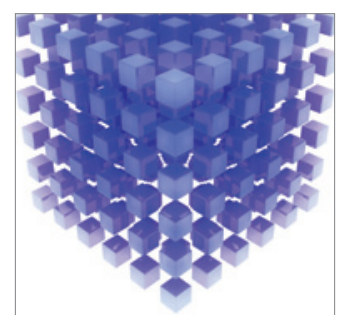

Mathematical Problems in Engineering
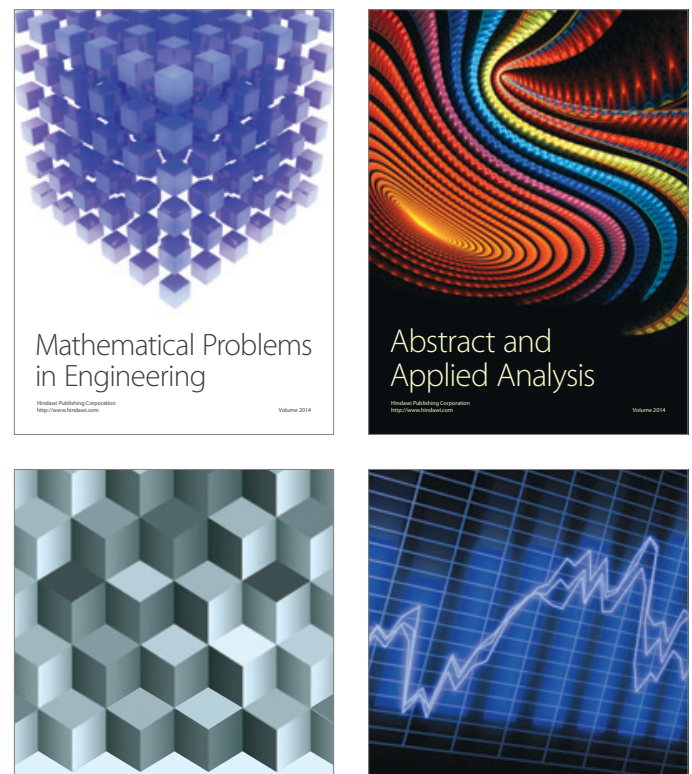

Journal of

Function Spaces

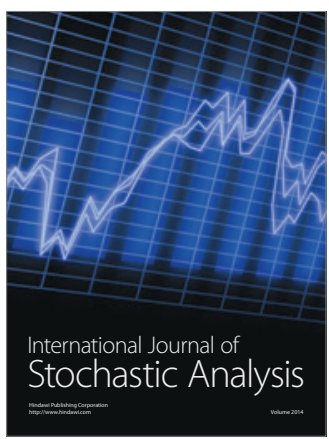

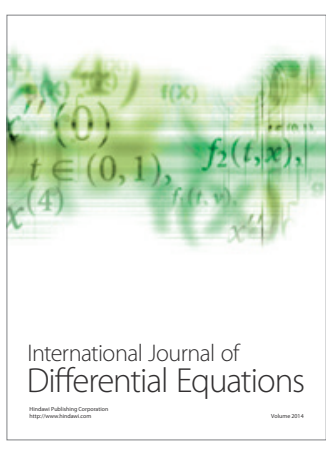
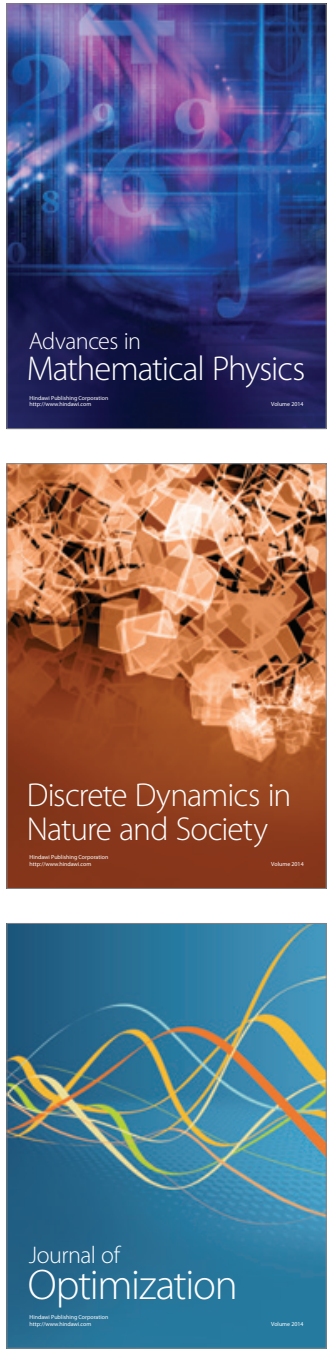